\title{
A Evolução Tecnológica e o Desenvolvimento das Cidades: 0 Potencial das Tecnologias Digitais no Gerenciamento das Cidades Contemporâneas
}

The Technological Evolution and the Development of Cities: The Potential of Digital Technologies in the Management of Contemporary Cities

La Evolución Tecnológica y el Desarrollo de las Ciudades: El Potencial de las Tecnologías Digitales en la Gestión de las Ciudades Contemporáneas

Roberta Betania Ferreira Squaiella Doutoranda, Universidade Presbiteriana Mackenzie, Brasil. robssquaiella@gmail.com.br

Roberto Righi Professor Doutor, Universidade Presbiteriana Mackenzie, Brasil. roberto.righi@mackenzie.br

Maria Victoria Marchelli Mestranda, University of Florida, Estados Unidos. mv.marchelli@ufl.edu 


\section{RESUMO}

O presente artigo evidencia o impacto do progresso tecnológico no desenvolvimento das cidades. Destaca-se a emergência do ciberespaço e o papel das tecnologias da informação e comunicação na configuração e no gerenciamento das cidades contemporâneas. As transformações propiciadas pela industrialização tiveram grande impacto no desenvolvimento das cidades, que passaram a receber grande concentração de pessoas, e possibilitaram o aprimoramento da infraestrutura e dos novos modais de transportes, foco de muitos projetos urbanos modernos. A segregação e o espraiamento das atividades na cidade, possibilitados por essa infraestrutura, foi alvo de grandes críticas no período pós-moderno, quando voltaram a valorizar o adensamento, a mistura de usos e a vida pública. Atualmente, com o grande desenvolvimento e a rápida propagação dos sistemas digitais, que se integram ao mundo físico e biológico, é necessário repensar novas formas de colaboração e de gestão das cidades.

PALAVRAS-CHAVE: Tecnologia. Cidades. Cibercultura.

\section{ABSTRACT}

The present article evidences the impact of technological progress on the development of cities. Highlight the emergence of cyberspace and the role of information and communication technologies in the configuration and management of contemporary cities. The transformations brought about by industrialization had a great impact on the development of cities, which began to receive a great concentration of people, and enabled the improvement of infrastructure and new modes of transportation, focus of many modern urban projects. The segregation and the spreading of activities in the city, made possible by this infrastructure, was the object of great criticism in the postmodern period, when they once again valued the density, the mix of uses and public life. Today, with the great development and rapid spread of digital systems, which integrate with the physical and biological world, it is necessary to rethink new forms of collaboration and management of cities.

KEYWORDS: Tecnhology. Cities. Ciberculture.

\section{RESUMÉN}

El presente artículo evidencia el impacto del progreso tecnológico en el desarrollo de las ciudades. Se destaca la emergencia del ciberespacio y el papel de las tecnologías de la información y comunicación en la configuración y la gestión de las ciudades contemporáneas. Las transformaciones propiciadas por la industrialización tuvieron gran impacto en el desarrollo de las ciudades, que pasaron a recibir gran concentración de personas, y posibilitaron el perfeccionamiento de la infraestructura y de los nuevos modales de transportes, foco de muchos proyectos urbanos modernos. La segregación y el despliegue de las actividades en la ciudad, posibilitadas por esa infraestructura, fue objeto de grandes críticas en el período posmoderno, cuando volvieron a valorar el adensamiento, la mezcla de usos y la vida pública. Actualmente, con el gran desarrollo y la rápida propagación de los sistemas digitales, que se integran al mundo físico y biológico, es necesario repensar nuevas formas de colaboración y de gestión de las ciudades.

PALABRAS CLAVE: Tecnologia. Ciudades. Cibercultura. 


\section{INTRODUÇÃO}

Segundo Benévolo (1999), após a segunda metade do século XVIII, a revolução industrial, iniciada na Inglaterra, transformou a sociedade em escala mundial. De maneira sucinta, os principais fatores que caracterizaram as transformações das cidades e dos territórios foram: 0 aumento da população e dos bens e serviços, a redistribuição populacional no território, o desenvolvimento dos meios de transporte e de comunicação. Tudo isto ocorre em grande velocidade, afastando-se do equilíbrio estável, deixando em aberto as possibilidades de novas mudanças cada vez mais profundas e rápidas.

Destacando-se as questões tecnológicas na organização das cidades, as transformações propiciadas pela industrialização tiveram grande impacto no seu desenvolvimento e possibilitaram o aprimoramento crescente de sua infraestrutura. Além disso, as cidades modernas, que foram constituídas ou reformuladas após a revolução industrial, se organizaram a partir da separação das funções das cidades: habitar, trabalhar, recrear e circular.

Após a Segunda Guerra Mundial, o modelo da cidade moderna passou a receber críticas. Dentre elas pode-se destacar a obra de Jane Jacobs de 1961, Morte e vida nas grandes cidades. Nela a autora evidencia, dentre outras questões, os problemas da falta de vida pública decorrentes da setorização das funções, da baixa densidade demográfica e da desvalorização do pedestre. Nesse cenário, as tecnologias que propiciaram o desenvolvimento e a valorização dos sistemas de transportes na mobilidade urbana foram vistas como ameaçadoras.

Ao final do século XX, o desenvolvimento tecnológico propiciou nova dinâmica na configuração e na gestão das cidades, devido a rápida propagação dos sistemas digitais de informação e comunicação. Para enfrentar os desafios e o impacto do crescimento urbano acelerado, foi criado o conceito de cidades inteligentes (em inglês, Smart City) que, apoiado nas redes de comunicação de massa, visa uma nova abordagem para ajudar a solucionar os problemas dos grandes centros urbanos, por meio de um processo de compartilhamento de informações, na sua construção e no seu desenvolvimento, de maneira mais sustentável. Entende-se, portanto, que o conceito de cidades inteligentes está apoiado no uso de tecnologias digitais na gestão das cidades, que precisa de adaptação das grandes metrópoles para solucionar os problemas urbanos e adequar a sua infraestrutura (ANDRADE e GALVÃO, 2016).

Do ponto de vista estrutural, a transformação dos meios de produção e transportes, assim como a emergência de novas funções urbanas, contribuem para romper com os velhos conceitos do projeto urbano. A adaptação da cidade, com as necessidades da sociedade, exige adequações para o progresso e a melhoria na vida urbana. Diante desse cenário, o presente artigo busca traçar as relações entre o progresso tecnológico e o desenvolvimento das cidades, destacando-se o papel das atuais tecnologias da informação e comunicação (TIC) no gerenciamento da cidade contemporânea. 


\section{AS TECNOLOGIAS E O DESENVOLVIMENTO DAS CIDADES INDUSTRIAIS}

Com as transformações no modo de vida da sociedade ao longo do tempo são constituídas as diferentes configurações do espaço urbano. Destaca-se que, após o período da Revolução Industrial ocorreram grandes inovações tecnológicas, que resultaram em importantes mudanças nas comunicações, nos transportes, na produção de bens e de consumo. Para Benévolo (1999), após a metade do século XVIII, a revolução industrial, iniciada na Inglaterra, transformou a sociedade em escala mundial, e os principais fatores que caracterizaram as cidades e os territórios, após esse período, foram: 1. O aumento da população, devido à redução no índice de mortalidade; 2 . O aumento dos bens e dos serviços, devido ao progresso tecnológico e ao desenvolvimento econômico; 3. A redistribuição populacional no território, devido ao aumento demográfico e as transformações da produção; 4. O desenvolvimento dos meios de transporte e de comunicação, como as estradas para automóveis, os canais navegáveis, as estradas de ferro, os navios à vapor, que possibilitaram grande mobilidade de pessoas e de mercadorias; 5 . A rapidez destas transformações que não alcançaram o equilíbrio estável, mas deixaram em aberto as possibilidades de transformações mais profundas e mais rápidas; e, 6. Nova forma de pensamento político que busca corrigir os defeitos atuais da cidade por meio de ações calculadas. Diante deste cenário, surge o urbanismo como uma nova disciplina, de caráter crítico e reflexivo. De acordo com Françoise Choay (1992), o neologismo urbanismo surgiu em 1910 e, com sua pretensão científica, buscava avaliar os planos de expansão da cidade industrial.

A partir do século XIX, muitos planos urbanísticos tiveram como objetivo organizar as cidades e oferecer melhores condições de vida para a população. Dentre eles, a experiência de Paris, proposta por Haussmann, foi a mais difundida e copiada de toda a história do urbanismo. Ressalta-se que cada cidade tem a sua peculiaridade e, portanto, transpor simplesmente um modelo de urbanismo, não resulta no mesmo sucesso daquele modelo copiado. A apropriação simplista, parcial e específica do conceito original do plano de Paris, apresentou diferentes resultados nas cidades onde foi replicado, pois, de modo geral, ocorreu como uma reprodução estética de cidade, que simbolizasse as características da cidade moderna ideal (SIMÕES JUNIOR, 2013).

Assim como o plano de Haussmann, outros planos urbanísticos, do início do século XIX, também foram adotados como modelo de planejamento e influenciaram a reestruturação urbana de várias cidades no mundo, sendo adotados como teorias normativas urbanas prémodernas e modernas. É o caso dos planos para as cidades de Barcelona, proposta por Ildefonso Cerdá, e de Viena, proposta por Ludwig Foster.

Muitos foram os impactos da revolução industrial nas cidades, que envolvem a complexidade da organização urbana, ampliação das redes de transportes e de comunicação e o consequente aumento dos fluxos de pessoas e de mercadorias. Nos transportes, a proliferação 
do uso do automóvel, dos balões dirigíveis, dos transatlânticos e, posteriormente dos aviões, possibilitaram o deslocamento cada vez mais rápido entre regiões distantes. No campo da comunicação, o cinema e o rádio revolucionam o modo de obter informações e de olhar para o mundo. Todas essas questões estão relacionadas a uma nova sociedade, que busca romper com o tradicionalismo da cidade medieval, densa e insalubre.

O grande desenvolvimento tecnológico deste período impactou no aprimoramento da infraestrutura dos novos modais de transportes nas cidades modernas, que tiveram o automóvel como o foco de desenvolvimento dos projetos urbanos (SOUSA, 2016). O automóvel é uma invenção industrial, do final do século XIX, e o seu aperfeiçoamento foi determinante na sua relação com a cidade (RIGHI; DINIS, 2011).

Dentro do ideário tecnológico, é possível destacar o CIAMs - Congresso Internacional da Arquitetura Moderna -, fundado em 1928 na Suíça, que foi responsável pela definição de uma arquitetura considerada limpa, sintética, funcional e racional. Nos congressos realizados, a arquitetura e urbanismo eram considerados como um potencial instrumento político e econômico, o qual deveria ser usado pelo poder público como forma de promover o progresso social. Em 1933 ocorreu o IV CIAM, no qual Le Corbusier escreveu a Carta de Atenas, que contém a síntese das proposições do urbanismo moderno. Os preceitos deste documento defendiam a cidade como um organismo a ser concebido de modo funcional, na qual deveria ocorrer a separação das atividades - de habitar, de trabalhar, de recrear e de circular - com grandes áreas verdes entre elas. Tais preceitos influenciaram o desenvolvimento das cidades europeias, após a Segunda Guerra Mundial e a criação do Plano Piloto de Brasília, de Lúcio Costa, no Brasil (SOUSA, 2016). Entretanto, a organização destas cidades recebeu muitas críticas no período pós-moderno.

\section{A CRÍTICA PÓS-MODERNA}

O período após a segunda guerra mundial foi marcado tanto pela aplicação dos princípios da Carta de Atenas, quanto pela oposição ao progresso como resposta aos problemas da cidade (SOUSA, 2016). Choay (1992) afirma que os fracassos do planejamento urbano, em tentar organizar as cidades industriais, gera contestações e críticas ao urbanismo. Dentre os críticos deste período é possível se destacar os autores como Henri Lefebvre, Cristopher Alexander e Kevyn Lynch que ressaltam as questões do espaço urbano e da vida pública. Além deles, a autora Jane Jacobs, com a sua obra Morte e vida nas grandes cidades (original de 1961, The death and life of great American cities), teve grande influência entre os urbanistas ao criar novas linhas de investigação no campo do saber científico, em vez de teorizar normas urbanas, como ocorreu com os urbanistas pré-modernos e modernos.

Jacobs expressa claramente a sua oposição aos fundamentos do planejamento urbano e da reurbanização vigentes naquele período. Para isso, ela apoia a sua crítica nos modelos de Cidade Jardim, de Ville Radieuse e de City Beautiful, planejadas, respectivamente, por 
Ebenezer Howard, Le Corbusier e Daniel Burnham. Produzidos pelo movimento moderno, esses modelos propuseram grandes malhas viárias, com a separação e o isolamento das atividades urbanas, o que teria acabado com os espaços e com a vida pública existentes nas cidades tradicionais (JACOBS, 2000). Corroborando com essa ideia, Righi e Dinis (2011) apontam que devido a primazia do automóvel, as políticas públicas das grandes cidades se submeteram a circulação individual de pessoas, que foi responsável pela degradação de extensas áreas urbanas e das relações sociais e culturais.

Ao fazer uma análise empírica da cidade, Jacobs destaca a necessidade de valorização e de apropriação do espaço público, a fim de se conseguir uma cidade mais segura e com espírito de vizinhança. Além disso, ela argumenta a favor do uso misto das funções, do adensamento, da valorização do percurso do pedestre e da combinação de edifícios de diferentes idades, em uma mesma rua ou distrito, como condições indispensáveis para gerar uma diversidade exuberante nas cidades (JACOBS, 2000). Tais questões despertaram o olhar dos críticos do urbanismo moderno, que passaram a propor um resgate das características da cidade tradicional.

Posteriormente, no final do século XX, as TIC proporcionaram novos impactos na relação com a cidade. Conforme apontado por Karssenberg e Laven (2015), atualmente a experimentação da cidade, por meio de novas experiências, estão se sobrepondo à distinção da sua funcionalidade. Assim como as cidades evoluíram, o campo do planejamento urbano também evoluiu, não havendo mais o planejamento de novas cidades, mas sim a reinvenção e reutilização das cidades existentes.

A análise da projeção populacional brasileira contribui com essa afirmação ao identificar o menor crescimento da população que, consequentemente, haverá menor necessidade de novas infraestruturas urbanas. De acordo com os dados do IBGE, nos últimos trinta anos o crescimento populacional brasileiro foi de aproximadamente 64 milhões de pessoas. Em 1988 havia aproximadamente 143 milhões de pessoas e em 2018, 208 milhões (IBGE, 2016 e 2018). No Gráfico 01 observa-se a projeção populacional, que considera um crescimento de 24 milhões de pessoas nos próximos 30 anos, com uma redução populacional na próxima década (IBGE, 2018). 


\section{Revista Nacional de}

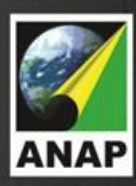

Gerenciamento de Cidades

Gráfico 01: Estimativa e projeção populacional no Brasil - 1988 a 2058

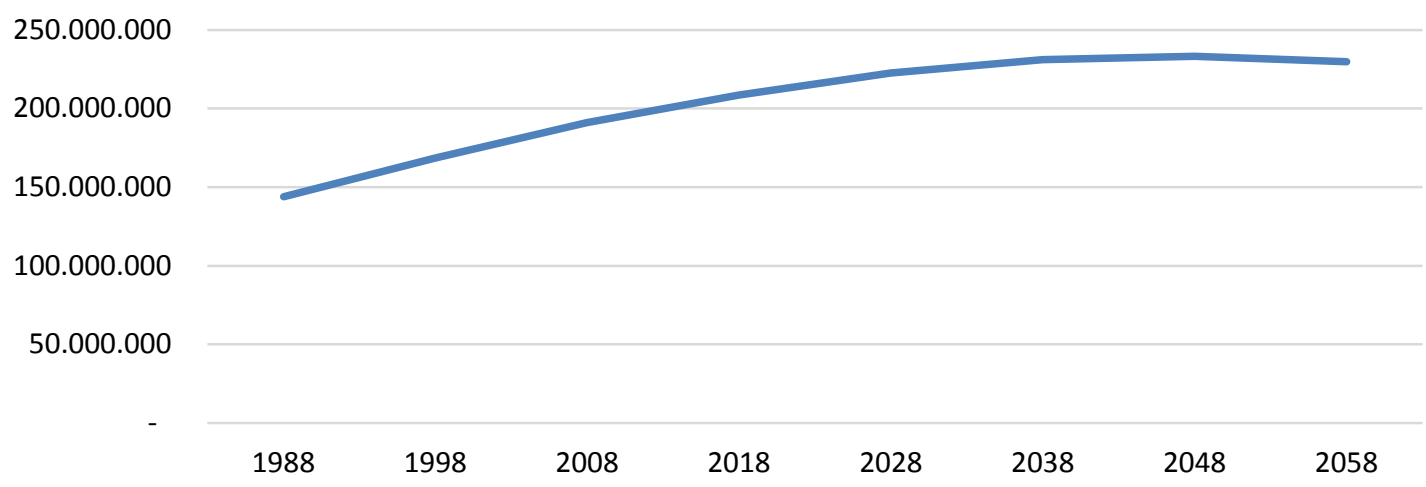

Fonte: IBGE, 2016 e 2018 (adaptado).

Atualmente, os projetos mais significativos de cidades estão fundamentados nos princípios de co-criação, que dependem de estratégias experimentais baseadas nos usuários e no lugar. Tais projetos mudam os padrões de parcerias e de municipalidades locais e regionais, além de envolverem vários grupos de usuários, como os membros de uma comunidade, os proprietários, os incorporadores, os empreendedores e as indústrias públicas e privadas. Apesar de ainda persistirem as novas construções e as áreas de crescimento nas cidades, deve ser predominante a reinvenção das estruturas urbanas existentes para acomodar o cenário de grandes transformações. Tais transformações podem ser expressas pelas seguintes questões: crescimento de famílias com diferentes composições e com uma ou duas pessoas; a competição entre as áreas comerciais e residenciais; interconectividade, em nível global, cada vez maior; crescimento da economia do conhecimento; e, o compartilhamento de bens e de serviços (KARSSENBERG; LAVEN, 2015). Isso provoca uma reavaliação da cidade como um todo e torna a experiência urbana cada vez mais importante.

\section{A CIBERCULTURA E AS NOVAS TERRITORIALIDADES}

Os investimentos na descoberta, na fabricação e na difusão das TIC têm sido cada vez maiores para o atendimento de uma demanda crescente de usuários e geram mudanças marcantes nas relações sociais, culturais, políticas e econômicas da sociedade contemporânea, que se conecta por meio das grandes redes da Internet. De acordo com André Lemos (2007), com o grande crescimento e desenvolvimento dessas tecnologias a sociedade é inserida em uma cultura da conexão generalizada, que propicia novas formas de apropriação do espaço urbano e de mobilidade social. Tal cultura foi definida por Pierre Levy (1999) como a cibercultura, considerada como um conjunto de técnicas materiais e intelectuais, de práticas, de atitudes, de modo de pensamento e de valores que se desenvolvem juntamente com o crescimento do ciberespaço, causando impacto nas diferentes relações econômicas, políticas e sociais. Apesar da cibercultura ser vista como uma ameaça para o espaço público, por agravar o processo de 
individualização, ela possibilita a interpretação de duas visões: de um lado a revolução tecnológica aponta que o espaço público teria perdido a sua função, pois mesmo conectado o homem vive isolado; por outro lado, é tido como a esperança de reencontro com o espaço público (SOUSA, 2016). Essa última visão vai de encontro com o que era defendido pelos críticos do urbanismo moderno.

Lemos (2007) afirma que o ciberespaço gera um processo de desterritorialização, porém também novas reterritorializações. Enquanto as redes telemáticas dissolvem todos os problemas de fronteira numa desterritorialização, elas também possibilitam reterritorializações a partir de novas dinâmicas de controle virtual sobre o espaço e o tempo. Destacando essa possibilidade de criar novos territórios, entende-se que as tecnologias de comunicação têm desempenhado um importante papel na construção de movimentos que vão desde grandes manifestações políticas até pequenas performances no espaço público (SOUSA, 2016). Por meio das comunicações em rede, as cidades são pensadas como formas de reestabelecer o espaço público e de reforçar os laços comunitários, fortalecendo a democracia contemporânea, de acordo com as diversas inteligências coletivas. Nelas vê-se a redefinição dos espaços público e privados, com a potencialização das trocas entre seus cidadãos e a ocupação de espaços concretos.

Por meio dos recursos de geolocalização, um conjunto de dispositivos, de sensores, de redes digitais sem fio e de seus respectivos bancos de dados, possibilita-se uma troca de relação dinâmica no espaço urbano, criam-se novos sentidos dos lugares e redimensionam-se as práticas sociais no espaço urbano. Nisto, elementos da infraestrutura urbana como a rua, a praça e a calçada perdem sua conotação tradicional e se integram com a rede de tecnologia, redefinindo-se como espaços de fluxo e não apenas lugares físicos (LEMOS, 2004). Para Lévy, as pessoas habitam todos os meios com os quais elas interagem, portanto habitam 0 ciberespaço da mesma maneira que a cidade geográfica, e isso é entendido como parte fundamental do ambiente global de vida contemporânea. "A organização do ciberespaço procede de uma forma particular de urbanismo ou de arquitetura, não física, cuja importância só irá crescer" (LÉVY, 1999, p. 196). Assim, articular o espaço físico e o ciberespaço visa compensar, dentro do possível, a inércia, a lentidão e a rigidez do território, solucionando os problemas da cidade por meio do compartilhamento de competências, de recursos e de ideias. Desta forma, avalia-se que as novas tecnologias digitais vêm favorecendo a velocidade da coleta e processamento das informações, permitindo interatividade com qualquer parte do mundo e consequentemente maior fluxo de informações e de conhecimentos. O conceito de compartilhamento, que ressalta o senso de comunidade e resgata práticas sociais cooperativas, permite o uso de bens, de espaços e de serviços de forma coletiva, como o uso compartilhado de espaços de trabalho, de transporte e de veículos alternativos que possibilitam facilidades na mobilidade urbana, redução do tempo gasto em grandes congestionamentos, redução das grandes distâncias entre a moradia e o trabalho, e a racionalização de despesas e de consumo (SANTOS, 2014). Exemplos dessas experiências 
cooperativas são os escritórios compartilhados, que apresentam um enorme crescimento nos últimos anos.

De acordo com o Censo Coworking Brasil 2018, após um crescimento de 114\%, em 2017, o segmento teve novo aumento de $48 \%$ em 2018, resultando em 1.194 escritórios de coworkings em todo o país, que atendem mais de 200 milhões de pessoas. Apesar da queda no ritmo, devido a novidade e escala, estes espaços estão em crescimento intenso. Com uma grande pluralidade no perfil dos espaços, há diferentes tipos de estruturas e de serviços, que atendem prioritariamente um mercado de trabalho multidisciplinar. Alguns coworkings funcionam 24 horas por dia, durante os sete dias da semana. Além do espaço físico flexível e das salas privativas para reuniões, há o suporte como: endereços virtuais, Internet de alta velocidade e equipamentos audiovisuais de última geração. O compartilhamento de espaços corporativos já atende cerca de $3 \%$ de todo o mercado global de escritórios, com uma previsão de chegar até $30 \%$ até 2030. São fatores que contribuem para o crescimento dos escritórios compartilhados: racionalizar os custos dos empreendedores, liberdade para trabalhar em um local descontraído, ampliação da rede social de trabalho (COWORKING, 2018). Além da possibilidade de novas relações como o espaço de uso público, as TIC contribuem para uma nova forma de utilização e de gestão urbana, como a que está ocorrendo nas cidades inteligentes.

\subsection{Cidades Inteligentes}

O conceito de cidades inteligentes (em inglês, smart cities) é a convergência da tecnologia com o desenvolvimento de cidades, que visa a gestão destas com qualidade de vida e competitividade econômica. Para isto, a cidade inteligente deve ser pensada como um sistema orgânico, que possibilite o inter-relacionamento de cada um dos seus subsistemas: transporte, energia, educação, saúde, edificações, infraestrutura física, alimentos, recursos hídricos e segurança pública. A interconexão consistente entre estas áreas ultrapassa a simples implantação de aplicações tecnológicas. Quanto melhores as conexões, maior é a inteligência de informações para a tomada de decisões, seja dos governos, seja da sociedade (STRAPAZZON, 2011).

Assim, o conceito de cidade inteligente está relacionado com a utilização das TIC para propiciar maior interação entre a cidade e os seus cidadãos. Isto significa uma correlação entre os aspectos técnicos (tecnologias inteligentes), recursos humanos (gestão inteligente de pessoas) e de governança (colaborações inteligentes), a fim de promover maior acessibilidade e eficiência da infraestrutura e dos serviços públicos em geral, com maior comprometimento com sua herança histórica e cultural, além da importante preocupação com o meio ambiente. Dois fatores importantes que impulsionam as cidades inteligentes são: o aumento da população mundial e a crescente urbanização. Tais fatores apontam para a preocupação com a evidente escassez de recursos naturais, que compromete a oferta global para a população 
mundial, além dos problemas relacionados ao meio ambiente e às constantes mudanças climáticas (AQUINO et. al, 2015). Hoje, a dinâmica da vida contemporânea leva a uma grande concentração populacional nas cidades, em busca de trabalho, de educação, de cultura, de saúde e de lazer. De acordo com as estimativas dos órgãos competentes, 84,36\% dos brasileiros viviam em cidades em 2013 (IBGE, 2014), 50\% da população mundial vivia em áreas urbanas (ONU, 2007) e, a previsão é de que em 2030 esta proporção seja de aproximadamente $60 \%$ da população mundial (ONU, 2012). Dentro deste cenário, que aponta como grande desafio minimizar o consumo de recursos energéticos naturais, promover a utilização de energias renováveis e reduzir a emissão de $\mathrm{CO} 2$, o conceito de cidade inteligente apresenta-se como uma ferramenta potencial para gerir de maneira eficiente a infraestrutura e os serviços da cidade (AQUINO et. al, 2015).

De acordo com Pavez et. al (2014), os recursos da Internet das coisas (como as informações públicas em tempo real, coleta eficiente de lixo e reciclagem, identificação de vagas livres em estacionamentos, captação de água da chuva, etc) tendem a minimizar os efeitos ruins da urbanização acentuada e diminuir maiores impactos ambientais sobre o planeta e as cidades. A evolução da Internet das coisas está se expandindo da dimensão de um meio de comunicação do sistema físico e passando a conectar objetos e pessoas a um sistema virtual. Através de sensores, ligam-se as linhas de produção, redes de transportes, redes de energias de residências, escritórios e veículos. A tendência é que por meio das tecnologias o uso dos produtos e serviços tudo seja cada vez mais compartilhado. Nesse aspecto, a construção do ambiente urbano compatível com a tecnologia passa a ser um desafio, considerando-se que esta última deve convergir com a cidade e não se apropriar dela, pois acredita-se que o ambiente virtual não substitui plenamente o ambiente real, mas interage com este. É importante considerar que as principais inovações tecnológicas irão alimentar uma enorme mudança em todo o mundo. As tecnologias emergentes e a inovação em grande escala têm se difundido de maneira mais ampla e numa velocidade mais rápida do que nunca. Além disso, as pressões demográficas, as mudanças geopolíticas, as novas normas sociais e culturais, transformarão a sociedade como um todo (SCHWAB, 2017).

Lemos (2010) destaca que, devido a expansão dos meios de transporte e das mídias de massa, a mobilidade torna-se questão central na discussão sobre o espaço urbano, desde as origens das primeiras organizações sociais, como a necrópole, até as cidades industriais do século XX. No século XXI, a cidade da informação e comunicação encontra na cultura da mobilidade o seu princípio fundamental: a mobilidade de pessoas, de objetos, de tecnologias e de informações sem precedentes. Assim, a mobilidade urbana é entendida como fator importante para o desenvolvimento das cidades, que buscam melhor qualidade de vida.

Considerando-se o longo caminho da gestão pública para tornar as cidades inteligentes, acredita-se em soluções da iniciativa privada que contribuem para o desenvolvimento inteligente da cidade. Desta forma, destaca-se a inserção das tecnologias para as ações remotas no trabalho e na educação, que juntos representam os maiores motivos de 
deslocamentos nas cidades, como ocorre, por exemplo, na Região Metropolitana de São Paulo. A educação a distância e o teletrabalho são alternativas viáveis e potenciais para a redução de deslocamentos e, consequentemente, apresenta contribuições para melhoria dos impactos prejudiciais na mobilidade urbana (SQUAIELLA; MARCHELLI; RIGHI, 2017).

Com os instrumentos de trabalho cooperativo em rede é possível participar da vida econômica local e até internacional a partir dos centros locais ou da própria residência. Destacam-se como benefícios disto: atenuação da poluição decorrente da redução de circulação de automóveis, diminuição dos congestionamentos urbanos, melhor distribuição das populações nos territórios, e melhoria da qualidade de vida. O custo social global da teleconferência é inferior ao de uma viagem efetiva e um posto de teletrabalho prescinde do escritório na cidade (LÉVY, 1999). Schwab (2016) também afirma que os custos de uma empresa digital tendem a zero, destacando-se que as empresas que trabalham com a tecnologia de maneira disruptiva, tendem a dispender de pouco capital para prosperar. Além disso, são praticamente nulos os custos para o armazenamento, o transporte e a replicação dos bens de informação.

Apesar do crescimento do ciberespaço nos tempos atuais, ainda não há descentralização intensa dos grandes centros urbanos, pois "o estudo das estatísticas mostra que as maiores densidades de acesso ao ciberespaço e de uso das tecnologias digitais coincidem com os principais núcleos mundiais de pesquisa científica, de atividade econômica e de transações financeiras" (LÉVY, 1999, p.185).

Assim, verifica-se que o adensamento urbano é outra questão, também destacada pelos críticos do movimento moderno, que atualmente se relaciona com a inserção das tecnologias, pois fundamenta-se no uso de menor espaço físico com altas densidades para consequentemente garantir melhores infraestruturas e minorar os impactos no meio ambiente. Em um mundo virtual, onde as barreiras físicas abstraem-se, o espaço ganha outras conotações e percebe-se que não é preciso incentivar o espraiamento urbano, pois são as tecnologias que se expandem centrifugamente e garantem as conexões. Destaca-se que a baixa densidade de ocupação do território de forma sustentável só é possível em padrões sociais elevados, devido ao alto custo da infraestrutura urbana. A maior parte da população deve viver de forma concentrada, sob altas ou médias densidades, para que os custos de urbanização possam ser socializados (MARCHELLI; SQUAIELLA; RIGHI, 2015). Assim, o modelo adensamento urbano permite menores infraestruturas, o que representa custos reduzidos, menor intervenção e impacto no espaço físico e possibilita maiores proximidades e contatos entre os habitantes da cidade.

Para Firmino e Duarte (2008), atualmente há uma infiltração das TIC na cidade, que trazem mudanças epistemológicas e sensoriais à vivência urbana e apontam para uma mudança radical do que se entende por cidade. $O$ crescimento do ciberespaço pode aumentar 0 controle sobre as redes econômicas, tecnológicas e humanas cada vez mais distantes e maiores, como também pode minimizar a separação física entre os interlocutores, por meio de nova maneira na organização cooperativa da comunicação, compartilhando e valorizando a 
inteligência entre as comunidades conectadas simultaneamente. Devido a isto, considera-se que no futuro as potencialidades das novas tecnologias podem romper o paradigma urbano desenvolvido até a atualidade.

Por fim, destaca-se que diante da alta velocidade das transformações tecnológicas é praticamente impossível prever as mudanças que ocorrerão num futuro próximo. Entretanto, deve haver maior integração com as TIC. Conforme apontado por Schwab (2016), o mundo digital, ramificado pela Internet, possibilita a integração física, digital e até mesmo biológica, por meio dos dispositivos móveis ou de dispositivos implantados nos seres vivos. Isso se dá graças ao surgimento sistemas de nanotecnologias, de neurotecnologias e de biotecnologia, que se tornam mais poderosos e mais baratos a cada dia. Por meio desses recursos, amplia-se o potencial de uso do big data, da inteligência artificial e da infinidade de possibilidade de programação das máquinas que impactarão toda a sociedade e, consequentemente, a cidade.

\section{CONSIDERAÇÕES}

As grandes transformações tecnológicas, impulsionadas pela industrialização, possibilitou a produção de bens e de serviços seriados e em larga escala, o que transformou as cidades em todo o mundo. Os sistemas de transportes e de comunicação foram os principais motivos de reorganização das cidades industriais, que buscaram romper com as características da cidade medieval, tida como insalubre, densa e desorganizada. Essa industrialização possibilitou o rápido desenvolvimento das cidades modernas e gerou novas formas de gestão urbana, que viabilizou a busca de uma renovação no ambiente construído. Porém, também permitiu a organização das funções por meio da setorização de atividades. A consequência disso foi alvo de crítica dos pós-modernos, que defendiam a volta de algumas das qualidades da cidade tradicional, como a utilização do espaço público, o adensamento urbano e a mistura de usos em uma mesma região.

Assim, compreende-se que os recursos tecnológicos causam grande impacto no desenvolvimento e na organização das cidades, desde o período industrial até a contemporaneidade. Mais recentemente, a rápida disseminação dos processos de informação e comunicação, por meio dos recursos das redes da Internet, produziu modificações profundas na sociedade e os avanços das novas tecnologias. Isto é visto como promissor no auxílio da organização dos espaços e das atividades, visando a racionalização do consumo de energia e dos demais recursos naturais, e a minoração dos efeitos negativos da urbanização acentuada que impactam o planeta.

Finalmente, é necessário repensar novas formas de colaboração e de gestão das cidades, com maior integração dos recursos tecnológicos, considerando-se o potencial da inteligência artificial, do big data, da robótica avançada, entre outras tecnologias. Essas tecnologias, que estão fundindo os mundos digital, físico e biológico, vão contribuir para o gerenciamento das cidades inteligentes, que se utilizarão cada vez mais das grandes redes de comunicação e dos 


\section{Revista Nacional de}

sistemas inteligentes de armazenamento e interpretação dos dados, que devem buscar o seu desenvolvimento mais sustentável.

\section{REFERÊNCIAS BIBLIOGRÁFICAS}

ANDRADE, Josiane Nascimento; GALVÃO, Diogo Cavalcanti. O conceito de smart cities aliado à mobilidade urbana. Revista Hum@nae, v. 10, n. 1, 2016.

AQUINO, André L.L.; Ramos, Heitor S.; Pereira, Leonardo V.; Frery, Alejandro C. Cidades Inteligentes, um Novo Paradigma da Sociedade do Conhecimento. São Paulo, Blucher, 2015. p. 165-178.

BENEVOLO, Leonardo. História da cidade. 3a ed. São Paulo: Editora Perspectiva, 1999.

CHOAY, Françoise. 0 urbanismo. 3a ed. São Paulo: Editora Perspectiva, 1992.

COWORKING Brasil. Censo Coworking Brasil 2018. Coworking Brasil.org, 2018. Disponível em: https://coworkingbrasil.org/censo/2018/. Acesso em: 10 out. 2018.

FIRMINO, R.; DUARTE, F. Cidade infiltrada, espaço ampliado: as tecnologias de informação e comunicação e as representações das especialidades contemporâneas. Arquitextos, 2008

IBGE, Instituto Brasileiro de Geografia e Estatística. Perfil dos municípios brasileiros 2013. Rio de Janeiro: IBGE, 2014.

IBGE, Instituto Brasileiro de Geografia e Estatística. Retroprojeção da população do brasil por sexo e idade: 20001980. Rio de Janeiro: IBGE, 2016.

IBGE, Instituto Brasileiro de Geografia e Estatística. Projeção da população do Brasil e Unidades da Federação por sexo e idade para o período 2010-2060. Rio de Janeiro: IBGE, 2018.

JACOBS, Jane. Morte e vida de grandes cidades. Martins Fontes, 2000.

KARSSENBERGE, H.; LAVEN, J. A cidade ao nível dos olhos: estratégia do plinth. Porto Alegre: EDIPUCRS, 2015.

LEMOS, André. Cibercultura e mobilidade: a era da conexão. Razón y palabra, v. 41, 2004.

LEMOS, André. Ciberespaço e tecnologias móveis: processos de territorialização e desterritorialização na cibercultura. Imagem, visibilidade e cultura midiática. Livro da XV COMPÓS. Porto Alegre: Sulina, 2007.

LEMOS, André. Celulares, funções pós-midiáticas, cidade e mobilidade. Revista Brasileira de Gestão Urbana, v. 2, n. 2, p. 155-166, 2010.

LEMOS, André (org). Cibercidade: As cidades na cibercultura. Rio de Janeiro: Editora e-papers, pp. 19-26. 2004.

LÉVY, Pierre. Cibercultura. São Paulo: Editora 34. 1999.

MARCHELLI, M. Victoria; SQUAIELLA, Roberta B. F.; RIGHI, Roberto. O papel do ciberespaço e das novas tecnologias da informação e da comunicação na melhoria da sustentabilidade do habitat urbano. In: $3^{\circ} \mathrm{CIHEL}$ - Congresso Internacional da Habitação no Espaço Lusófono. São Paulo: FAU USP, 2015.

ONU, Organização das Nações Unidas. UN-HABITaT. The United Nations perspective on reinventing planning. 2007, p. 15-34 


\section{Revista Nacional de}

ONU, Organização das Nações Unidas. Rio+20: 0 futuro que queremos. Fatos sobre as cidades. Rio de Janeiro, 2012.

PAVEZ, Cristienne Magalhaes; DETROZ, Djessica; VIANA, Anna Paula. Cidades sustentáveis, inteligentes e inclusivas: reinvenção das cidades. Revista de Extensão e Iniciação Científica SOCIESC-REIS, v. 1, n. 1. 2014.

RIGHI, Roberto; DINIS, Henrique. O automóvel e o desenvolvimento regional Metropolitano de São Paulo, Brasil. In: BALEIRAS, Rui Nuno. Casos de Desenvolvimento Regional. Cascais, Portugal: Principia, 2011. Pg. 237 a 252.

SANTOS, Claudia Maria Neme dos. Coworking: contribuições de um modelo de consumo colaborativo e da arquitetura corporativa para o gerenciamento das cidades. Revista Nacional de Gerenciamento de Cidades, v. 2, n. 12. 2014.

SCHWAB, Klaus. A quarta revolução industrial. São Paulo: Edipro, 2016.

SIMÕES JUNIOR, José Geraldo. O ideário haussmanniano e sua difusão no Brasil: os projetos urbanos para as capitais brasileiras no início da República. In: Anais do Encontros Nacionais da ANPUR, v. 13, 2013.

SOUSA, Octávio dos Santos. Cibercultura e ocupações no vazio moderno em Brasília. Dissertação de mestrado (arquitetura e urbanismo) da Universidade de Brasília. 2016.

SQUAIELLA, Roberta Betania Ferreira; MARCHELLI, Maria Victoria; RIGHI, Roberto. Perspectivas do EAD e do teletrabalho na melhoria da mobilidade urbana da Região Metropolitana de São Paulo (RMSP). Revista Nacional de Gerenciamento de Cidades, v. 5, n. 29, 2017.

STRAPAZZON, Carlos Luiz. Convergência tecnológica nas políticas urbanas: pequenas e médias "cidades inteligentes". Revista Jurídica, v. 22, n. 6, p. 89-108. 2011. 